\title{
Der fließende Gellert und der spitzige Rabener
}

Thematisierung von Anonymität und Autorschaft als Strategie der Selbst- und Werkpolitik in faktischen, fingierten und modifizierten Briefen

Douceur de la poésie chez Gellert et causticité de la satire chez Rabener.

Anonymat et identité comme stratégies de politique éditoriale et personnelle des auteurs dans leurs lettres authentiques, fictives ou retravaillées

The "(fluid-)moving" Gellert and the "spiky" Rabener. Anonymity and authorship as a strategy of self- and opus-politics in factual, fictional and modified correspondence

\section{Nadja Reinhard}

\section{(2) OpenEdition}

\section{Journals}

Édition électronique

URL : http://journals.openedition.org/ceg/943

DOI : $10.4000 /$ ceg.943

ISSN : 2605-8359

Éditeur

Presses Universitaires de Provence

Édition imprimée

Date de publication : 30 mai 2016

Pagination : 161-182

ISBN : 979-10-320-0067-0

ISSN : 0751-4239

Référence électronique

Nadja Reinhard, « Der fließende Gellert und der spitzige Rabener », Cahiers d'Études Germaniques

[Online], 70 | 2016, Online erschienen am: 17 Dezember 2017, abgerufen am 26 November 2020. URL: http://journals.openedition.org/ceg/943; DOI : https://doi.org/10.4000/ceg.943 


\section{Der fließende Gellert und der spitzige Rabener Thematisierung von Anonymität und Autorschaft als Strategie der Selbst- und Werkpolitik in faktischen, fingierten und modifizierten Briefen}

Nadja REINHARD

Universität Innsbruck

Die Thematisierung der (eigenen) Autorschaft ist für die Selbst- und Werkpolitik von Autoren unerlässlich. In der im 18. Jahrhundert ausgeprägt gepflegten Briefkultur bieten faktische, fingierte und modifizierte Briefe unter gezielt gewählter Onymität, Anonymität oder Teilanonymität mittels Siglen, z.T. auch explizit begründet, vielfältige Möglichkeiten, die eigene Selbstwahrnehmung und Werkrezeption zu steuern oder zumindest aktiv zu beeinflussen. Maßgeblich für die Beurteilung von Rezipientenseite ist die Differenzierung in Bezug auf den Adressatenkreis unter Berücksichtigung des jeweils beabsichtigten bzw. des dann faktisch erlangten Grades an Öffentlichkeit, so hinsichtlich der für den Freundeskreis oder erweiterten Bekanntenkreis bestimmten (teilöffentlichen) Privatbriefe sowie den für die breite Öffentlichkeit zugänglichen fiktiven oder für Drucklegung autorisiert modifizierten Briefen bzw. Briefwechseln. Allerdings steuern in der modernen Beschleunigung der schriftstellerischen Produktion im Takt der Messen, wie sich am Beispiel Gellerts und Rabeners gleichfalls zeigen lässt, auch gerade unautorisierte Erscheinungsweisen die Rezeption der Autoren maßgeblich und nachhaltig, so die zum Teil willkürlich modifizierten und unautorisiert veröffentlichten Briefe sowie posthum erscheinende Autordarstellungen, die sich durchaus auch die durch die Briefform suggerierte Authentizität zu Nutze machen (so im Falle Mauvillon-Unzers). Im Falle Gellerts und Rabeners führt dann vor allem die Rezeption seit dem im frühen 19. Jahrhundert in Anschluss an die Darstellung des als Klassiker-Autor und Autorität anerkannten Goethe in Dichtung und Wahrheit zu einem verzerrten Autorbild, das die einst berühmten, hoch angesehenen und vielgelesenen Klassiker-Autoren zu Topoi in Vergessenheit geratener Dichter verkommen lässt. Das Folgende lässt sich als kleiner Beitrag zu einer Rezeptions- und Kulturgeschichte epistolarer Selbst- und Fremdinszenierung lesen. 


\title{
Ueber den Werth einiger Deutschen Dichter und über andere Gegenstände den Geschmack und die schöne Litteratur betreffend
}

\begin{abstract}
Es ist nie ein Schriftsteller gewesen, der die Denkungsart und Sitten seiner Zeit so gut gekannt hätte, wie Rabener [...] und das Vorurtheil fand auch in den heiligsten Freystädten keinen Schutz für seinen Spott. Aber das war ein Spott, der, wenn er Wunden schlug, auch gleich das heilende Salz bey sich führte, und eben so sehr das Zwergfell als die Galle erregte. Daher kams, daß ein jeder, der sich nur etwas über den gemeinen Mann erhob, sich schämte Rabeners Satyren nicht in seiner Bibliothek zu haben; und, indeß die Söhne und Töchter des Hauses beim Gellert zärtliche Thränen vergossen, saß der weisere Vater bei seinem Freunde Rabener, und ließ sich lachend die schwersten Pflichten des Bürgers, des Ehemanns und des Hausvaters von ihm lehren. Ja, er war der Lieblingsschriftsteller des Publikums zu einer Zeit, da die Litteratur noch nicht ausgebreitet war; und der Mannigfaltigkeit, dem muntern Witze, und der Wohlredenheit seiner Schriften hat man es zu verdanken, daß der gute Geschmack in Deutschland etwas allgemeiner geworden ist. [...] Rabener ist viel geschickter dazu, ein klassischer Schriftsteller der deutschen Sprache zu heißen, als Gellert [...]. ${ }^{1}$
\end{abstract}

Ein Jahr zuvor in dem unter Schubarts Herausgeberschaft in den Schwäbischen Beyträgen zu Gellerts Epicedien (1770) anonym erschienenen Nachruf, als dessen Replik anlässlich Rabeners Tod die Rabener und Gellert betreffenden Ausführungen im Dreizehnten und Vierzehnten Brief bei Mauvillon/Unzer verstanden werden können, hieß es hingegen von Gellert:

Satyre ohne Beleidigung; Salz ohne ätzende Lauge; Klarheit ohne Wasser; Poesie ohne Schwulst und eine Versifikation, die wie ein Bach durch Blumen fleußt, alle diese Vorzüge erwerben unserm Gellert den Rang eines der ersten klassischen Schriftsteller. ${ }^{2}$

Dass Mauvillon/Unzer in ihrem 1771 begründet anonym veröffentlichten Pamphlet Ueber den Werth einiger Deutschen Dichter und über andere Gegenstände den Geschmack und die schöne Litteratur betreffend - als quasi im Schaukelstuhl verteilte (Brief-)Weisheiten mit einem „kunstrichterlichen Anstrich“ ${ }^{3}$ - Rabener vor Gellert den Vorzug geben, ist in erster Linie dem Stil beider Autoren und dem eigenen Programm ihres fiktiven Briefwechsels geschuldet; eine „wahrhaftig thätige[.] Menschenliebe“ ${ }^{4}$ als Beweggrund ihrer schriftstellerischen Tätigkeit wird beiden gleichermaßen zuerkannt. Rabeners wohldosierte Bissigkeit entspricht dabei (mutmaßlich) - das Wirkungspotential und seine Aussageweise wie seine Einkleidung betreffend - dem in dem Pamphlet selbst angestrebten Stil und Zielen. Mittels der ansonsten schon „so abgenutze[n] Erfindung [einer...]

1. Anonym [Jakob Mauvillon; Johann Jakob Unzer], Ueber den Werth einiger Deutschen [!] Dichter und über andere Gegenstände den Geschmack und die schöne Litteratur betreffend, Ein Briefwechsel, Erstes Stück, Frankfurt und Leipzig 1771, S. 296-298.

2. Anonym [Christian Daniel Schubart?], „Einige Züge von Gellerts Charakter“, in Christian Daniel Schubart (Hrsg.), Schwäbische Beyträge zu Gellerts Epicedien, Stutgart [!], 1770, S. 1-10; hier S. 5 .

3. Anonym, Ueber den Werth einiger Deutschen Dichter, S. 25.

4. Ibid., S. 282. 
Einkleidung in Briefen " 5 soll dort nämlich durch eine möglichst authentische Fiktion eines „Privatenbriefwechsels unter sehr guten Freunden“ ${ }^{6}$ unverblümte Wahrhaftigkeit gewährleistet werden. Durch die gewählte Briefform soll die sonst bei einer mitgedachten Veröffentlichung immer greifende Zensur und Rücksichtnahme eben gerade ausgeblendet und „durch Bekanntmachung ihres Briefwechsels richtigere Begriffe und gegründetere Urtheile an die Stelle der gewöhnlichen "7 in Direktheit und Schärfe gesetzt werden. Nicht zuletzt schreiben sie auch gegen die mit Gellerts Tod einsetzende Flut von in Intensität und Quantität beträchtlichen, wenn auch nicht singulären Trauerbekundungen an, die zwar mit gängigen Topoi des ,Schmerzes der ganzen Nation“ operieren, aber - gegenüber einer sonst eher lokalen Begrenztheit - sich über den Leipziger Schwerpunkt hinaus auf ganz Deutschland verteilen, „auf die unterschiedlichsten Städte und Territorien im Alten Reich, von Hamburg über Frankfurt/Main und Augsburg bis Wien und von Stuttgart und Karlsruhe über Nürnberg und Berlin bis Hirschberg“ und so grundsätzlich als ein „vom breiten Publikum mitgetragenes Massenphänomen“, „auf einen tiefgreifenden Wandel hinsichtlich der Trägergeschichten der gelegenheitsliterarischen Produktion“" verweisen, in dem sich die Autoren der Trauerschriften nicht zuletzt selbst inszenieren. Anonymität und Briefform werden in der Vorrede Mauvillon/Unzers ausführlich begründet und entgegen einer sonst üblichen Selbstinszenierung der Autoren mit der namentlichen Selbstzurücknahme durch Wahrung der Anonymität in den Dienst der Wahrheit und ihrer Sache gestellt; gleichwohl werden sie damit faktisch aber gezielt zur Selbst- und Werkpolitik genutzt, wenn Mauvillon/ Unzer den Vorwurf, „daß sie sich durch einen Angrif auf angesehene Männer hätten berühmt machen wollen“9 vorwegnehmend, ihre „gemeinnützigere[n] und wichtigere[n] Gegenstände“ - für die die Unbekanntheit Ihrer beider Namen bürge - als Mittel der Distinktion gegen den „ausgebreiteten Ruf eines Gleims, Jacobi und Spaldings“ herausstellen. ${ }^{10}$

Die Verfasser dieser Briefe sind ganz unpartheyisch. Sie stehen nicht in der geringsten Verbindung mit einer Parthey, ja sie haben nicht einmal die entfernteste Bekanntschaft mit irgend einem schönen Geiste, deren Freundschaft sie auch vielleicht sehr wenig geneigt sind zu suchen. Denn wozu? Um etwa an ihren Streitigkeiten und Zänkereyen, womit sie sich zum Gespötte der Vernünftigen machen Theil zu nehmen? Gott behüte! die Bekanntschaft mit ihren Schriften ist alles, was erforderlich ist. In dieser Verfassung urtheilen sie nun unter sich vollkommen frey, ohne alle Zurückhaltung und Rücksicht auf irgend eine Person. ${ }^{11}$

Als Strategie vermeintlicher Geheimhaltung und Privatheit wird das Setting des fiktiven Privatbriefwechsels sowie einer ausführlich kommentierten Anonymität

5. $\quad$ Ibid., S. 3.

6. Ibid., S. 13.

7. Ibid., S. 19.

8. Ralf Georg Bogner, „Gellert oder: Der Nachruf im Kult der Empfindsamkeit“, in ders., Der Autor im Nachruf, Formen und Funktionen der literarischen Memorialkultur von der Reformation bis zum Vormärz, Tübingen, Niemeyer, 2006, S. 255-302; hier S. 260, 262, 256.

9. Anonym, Ueber den Werth einiger Deutschen Dichter, S. 26.

10. Ibid., S. 11.

11. Ibid., S. 21 . 
geschickt genutzt, um die Neugierde und Enträtselungslust beim Publikum anzuregen sowie Brisanz und Authentizitätscharakter der Briefe zu bekräftigen:

Der Herausgeber dieser Schrift hält sich auch daher [da die Schrift nicht gemäß der unterstellten Publikumserwartung vollkommen ausgearbeitet ist] für verpflichtet, dem Leser zu versichern, daß der eine von diesen Freunden würklich seit geraumer Zeit der schönen Literatur untreu gewesen, und von dem andern unwillkürlicher Weise in ein für ihn fremdes Fach gezogen worden ist, dieser andre aber zuviel Bescheidenheit besitzt, als daß er ohne die heiligste Versicherung der Geheimhaltung seines Namens zur Herausgabe dieser vertrauten Briefe eingewilligt haben würde. ${ }^{12}$

\section{Christian Fürchtegott Gellert/Gottlieb Wilhelm Rabener - Original und genialischer Dichter?}

In Ueber den Werth einiger Deutschen Dichter wird Gellert zwar gleichwohl das Verdienst zuerkannt, „den itzt herrschenden Geschmack an der Lesung schöner Schriften in Deutschland eingeführt“ ${ }^{13} \mathrm{zu}$ haben und auch seien „Gellerts Grundsätze in der Moral sicherlich von dem größten Nutzen "14, allerdings gelte das nur „für eine gewisse Classe von Menschen“"15, für die der Einsatz als Therapeutikum gegen männlich-menschliche Rohheit sehr nützlich sei. Als einer „männlichen Seele für unwürdig“ und im Falle der Ausbreitung auch „einem Staate höchst gefährlich“ werde die „Einsaugung [!] der Gellertschen Grundsätze“ für der Natur nach sympathetisch-einfühlsame Herzen hinsichtlich eines dann drohenden „hohen Grade[s] von weibischer Kleingeisterey“ ${ }^{16}$. Für seine gute Absicht - d.i. den „Menschen in der Tugend das wahre Mittel zum Glück zu zeigen, und sie, durch Bildung des Herzens, zum Genusse dieses Glückes geschickt zu machen“ - habe Gellert „in der Ausführung derselben [freylich etwas gefehlt]“ ${ }^{17}$. Entgegen Rabeners „männlichern Schönheiten“ ${ }^{18}$ wird Gellerts von „Ausdehnung, [...] Einförmigkeit und Seichtheit“ ${ }^{19}$ geprägter „Styl“ als geschmacklich überholt empfunden und sei ohne „wahre[.] dichterische

12. Ibid., S. 9.

13. Anonym, Ueber den Werth einiger Deutschen Dichter, S. 281. „Es ist nehmlich durch sie [Gellerts Werke] der Geschmack am Lesen weit allgemeiner in Deutschland geworden, als vorher. Alles, was sich nur ein wenig über den Baurenstand erhebt, ließt anjezt, und ließt vor allen Dingen Gellerts Schriften.“ (Ibid., S. 303).

14. Ibid., S. 282.

15. Ibid., S. 289.

16. Ibid., S. 283. „Gellerts Schriften sind, deucht mir, von der Seite ihres Nutzens weniger Leuten von weicher Empfindung zu empfehlen, als solchen, deren Temperament noch viel Hartes in seiner Mischung hat, die von Natur eine Anlage zu einer gewissen Art Strenge besitzen, welche ungebildet leicht in Rauhigkeit ausarten könnte [...] sie söhnen sie, so zu sagen, mit der Menschlichkeit aus, und verschaffen ihnen jene mittlere Denkungsart, die das Herz nach Grundsätzen zu einer wahrhaftig thätigen Menschenliebe erwärmt, und dem Gefühl seine Rechte gönnt, ohne deswegen die männliche Vernunft unter ihren Rang zu erniedrigen.“ (Ibid., S. 281f.)

17. Ibid., S. $284 \mathrm{f}$.

18. Ibid., S. 299.

19. Ibid., S. 298. 
Schönheiten“20, weswegen die Lektüre von Gellerts Schriften die Nation geschmacklich eher zurückwerfe. ${ }^{21}$ Dem entsprechend stoßen sich die anonymen Briefschreiber am meisten an Gellerts Selbstinanspruchnahme des Genie-Begriffs, den sie in Bezug auf deutsche Autoren nur als relative Größe verwenden - so zur positiven Abgrenzung Rabeners gegen Gellert ${ }^{22}$ - und den sie als absolute Größe für die Engländer Shakespeare und Milton reserviert haben, deren Verehrung als einzig wirklich genialische Autoren allein nicht übertrieben sei. ${ }^{23}$

\begin{abstract}
Wenn man zur Bildung des Geschmacks einer Nation beytragen oder derjenige Mann seyn will, den unser Publikum in Gellerten verehrt, nämlich einer, der die Barbarey vertreibt, und an deren statt Erleuchtung und Geschmack setzt; so gehört dazu nothwendig ein Mann von einem ganz außerordentlichen Genie, und wir haben aus allen möglichen Umständen gesehn, daß dies Gellert gar nicht war. ${ }^{24}$
\end{abstract}

Vor dem Hintergrund einer grundsätzlichen angemahnten Überbewertung der Person des Autors gegenüber dem tatsächlichen Verdienst seines Werkes liest sich bereits die noch allgemein gehaltene, auf den Genie-Anspruch junger Dichter rekurrierende Passage in ihrer Vorrede als gezielte, wenn auch implizite Invektive gegen Gellert als ,Lehrer der ganzen Nation“ sowie seine gegenüber Friedrich II. in Anspruch genommenen Selbststilisierung als deutsches Original:

Soviel ist gewiß, unsere jungen Genies ersticken in der Blüthe. Sie suchen das Fremde, nicht das Schöne. Das Wort Original schallet ihnen in den Ohren; das wollen sie seyn. [...] Ein Genie fühlt sich, und läßt sich durch einen ganzen Schwarm von Critikern nicht irre machen. Der Fehler ist immer noch, daß man bloß nach dem Rufe, den Leute von sich haben, und nicht nach dem Verdienste des Werks selbst abgemessen ist, das heraus kömmt. ${ }^{25}$

Schubart sieht den guten Geschmack gerade an die von einem ,wohltätigen Genius gesandten‘ Dichter Hagedorn und Gellert gebunden, die er als moderne, den Schweizern verbundene Gegenmodelle $\mathrm{zu}$ dem tonangebenden und der Wahrscheinlichkeit verpflichteten Herrschertypus Gottsched versteht:

Der Geschmack des deutschen Publikums war zu der Zeit, als Gellert auftrat, gänzlich verdorben. [Gottsched, vielleicht zu stolz und kein Genie hatte sich ...] zum Areopagen des guten Geschmacks in Deutschland auf[geworfen]. Haller und Bodmer wurden niedergedonnert [...]. Aber ein wohltätiger Genius sandte uns einen Hagedorn und Gellert, und der gute Geschmack fieng mitten in der Nacht zu leuchten an. ${ }^{26}$

Aus der Perspektive eines erbitterten Konkurrenzkampfs unter Schriftstellern und Autorengruppen nach 1800 erscheint die Zeit von 1740-1760 allerdings

20. Ibid., S. 307.

21. Ibid., S. 305. „Der einzige Unterschied, den ich darinn sehe, ist der, daß man sonst nichts las, und anitzt was schlechtes ließt. Der Geschmack der Nation ist dadurch nicht um ein Haar weiter, sondern vielmehr zurückgekommen.“ (Ibid., S. 306).

22. Die Nation widme „einem Gellert ihre ganze Verehrung, alle ihre Klagen [...], und das gößere Verdienst Rabeners, sein vortrefflichers Genie und seinen originellern Geist“ vergesse sie ungepriesen. (Ibid., S. 296).

23. Ibid., S. 290.

24. Ibid., S. 301.

25. Anonym, Ueber den Werth einiger Deutschen Dichter, S. 15f.; $18 \mathrm{f}$.

26. Anonym, Einige Züge von Gellerts Charakter, S. 3. 
dennoch als ein goldenes, d.h. als ein von gegenseitiger Achtung im literarisches Feld geprägtes literarisches Zeitalter gemessen an dem auf die „Diversifikation der Leserbedüfnisse“ reagierenden Buchmarkt, der „zu einer zunehmenden Dichotomisierung der Literatur“ und damit zum Verlust eines gemeinsamen Ziels zur Besserung der Leser führt. ${ }^{27}$ Gellert ist vermutlich der meistgelesene Autor des 18. Jahrhunderts und seine in zwei Bänden 1746 und 1748 publizierten Fabeln zählten zu den bekanntesten Büchern ${ }^{28}$ ebenso wie die von seinem engsten Freund Rabener in vier Bänden publizierte, zu Lebzeiten sehr berühmte Sammlung satyrischer Schriften (1751-1755). Herder vergleicht Gellert in Bezug auf die öffentliche Ausstrahlung seiner Person und die damit einhergehende Anziehungskraft auf das Publikum - der epochenspezifischen Unvergleichbarkeit zu trotz - mit Homer ${ }^{29}$, Meyer-Krentler spricht von einem „beispiellosen nachliterarischen Wirken zu Lebzeiten“, das Gellert zur „Inkarnation seiner literarischen Botschaft“ machte. ${ }^{30}$ Seine „sprichwörtliche Volkstümlichkeit [...] erklärt sich aus dem Kontext von ,Volksaufklärung. Diese ist [...] sein Programm und zugleich Bedingung und Ziel seiner gelingenden Wirkung“, als Gegenbild zu Gottsched (als Herrscher) und Goethe (als Olympier), der gerade „in seiner Lebensführung seine poetische Botschaft“ fortsetzt und als volksnaher Dichter „Zuspruch, Rat und Trost“" spendet. ${ }^{31}$ Dem entsprechend lobt Schubarts Nachruf seinen „populairen und allgemeinverständlichen Ton“, der „sich des Geists seiner Nation [...] bemächtigt“ habe sowie als charakteristische Züge seiner „Muse [...] Unschuld, Zärtlichkeit, gefälliges Lächeln, brünstige Tugend“32. Seine geistlichen Lieder seien „wirklich unvergessliche Denkmale seiner Tugend und seines geläuterten Christenthums [...]. Seine Briefe sind natürlich,

27. Uwe Hentschel, „Was will die Poesie Gellerts im 19. Jahrhundert?“, in Sibylle Schönborn / Vera Viehöver (Hrsg.), Gellert und die empfindsame Aufklärung. Vermittlungs-, Austausch- und Rezeptionsprozesse in Wissenschaft, Kunst und Kultur, Berlin, Erich Schmidt Verlag, 2009, 273-283; hier 274. „Man hat die Zeit, wo Klopstock seinen Messias sang, wo Uz, Gellert, Kleist, Hagedorn, Gleim, Ramler, Wieland und einige Andere ihrer Zeitgenossen am literarischen Himmel Deutschlands glänzten, als das goldne Zeitalter unserer Dichtkunst gepriesen.“ (August Mahlmann, „Ueber das goldne Zeitalter der deutschen Literatur“, in Zeitung für die galante Welt, Heft 5, 1. Stück, 5. Januar 1805, S. 17).

28. „Frag die erste, beste Landpredigertochter nach Gellerts Fabeln? die kennt sie - nach den Werken andrer unsrer berühmten Dichter? kein Wort." (Thomas Abbt, Vom Verdienste, Berlin, 1765, S. 376 f.). Eine statistische Übersicht über die im bei Adelung zitierten Werke Gellerts, dessen Rezeptionspraxis unter Vorbehalt auch Rückschlüsse auf den Bekanntheitsgrad der Schriften erlaubt, gibt Mühlenhort Michael, „Das Grammatisch-kritische Wörterbuch von Johann Christoph Adelung“, in Schönborn / Viehöver, Gellert und die empfindsame Aufkärung, S. 153-173, hier S. 166. Dabei machen die Lustspiele 58\%, die Moralschriften mit knapp 23\% und die Fabeln mit 13\% fast 95\% der Nennungen aus, der Briefsteller ist allerdings mit nur knapp 1\% vertreten.

29. Johann Gottfried Herder, Über die neuere deutsche Literatur. Fragmente, Zwote Sammlung, IV B, in ders., Sämtliche Werke, hrsg. von Bernhard Suphan, Berlin, Weidmann, 1877-1913, Bd. 1, S. $301 \mathrm{f}$.

30. Eckhardt Meyer-Krentler, „‘...weil sein ganzes Leben eine Moral war. Gellert und Gellerts Legende“, in Bernd Witte (Hrsg.), „Ein Lehrer der ganzen Nation“. Leben und Werk Christian Fürchtegott Gellerts, München, Fink, 1990, S. 221-257; hier S. 221.

31. Meyer-Krentler, Gellert und Gellerts Legende, S. 237.

32. Anonym, Einige Züge von Gellerts Charakter, S. 4. 
leicht und ungezwungen." 33 In Anspielung auf Gellerts durch unautorisierte Veröffentlichung bekannt gewordene briefliche Darstellung seiner Audienz bei Friedrich dem Großen lässt Schubart den „Vorwurf des Französismus“ anklingen, ohne den er (insofern tatsächlich berechtigt) allenfalls „ein noch größeres deutsches Original geworden seyn [würde], als er wirklich ist." ${ }^{34}$ Nach seiner Herausstellung von Gellerts Person - als Lehrer für Verstand und Herz, als Freund, als Unterthan, d.i. hier als schlagendes „Beispiel des Patriotismus“ sowie als Christ, gemäß seiner Menschenliebe endet der Nachruf auch mit einem von Gellert selbst exponierten Zitat Friedrichs, der ihn als den „Vernünftigsten unter den Deutschen“ bezeichnete. ${ }^{35}$

Auch Rabener wird von seinen Zeitgenossen gefeiert: Johann Adolf Schlegel (1721-1793) stellt die Kunst der Mannigfaltigkeit von Rabeners Satyrischen Briefen heraus ${ }^{36}$, Friedrich Gottlieb Klopstock (1724-1803) verleiht Rabener in seiner Wingolf-Ode den Beinamen des „Gerechten“"37. Karl Wilhelm Ramler (1725-1798) nennt Rabener seinerseits einen „lachenden satirischen Genius, männlich schön in seiner Schreibart, ganz unerschöpflich in seinen Erfindungen “ ${ }^{38}$. So sprechen auch Mauvillon/Unzer Rabener als Autorperson eine umfassende gesellschaftlich-nationale Kompetenz zu, dessen „sehr wesentlichen Einfluß auf Deutschland“ das - entgegen der auch posthum anhaltenden Wertschätzung Gellerts - (ungebildete und damit blind urteilende) Publikum allerdings mit Undank strafe, wovon vor allem die nicht erfolgte Reaktion auf Rabeners Tod (1771) zeuge:

\footnotetext{
Und eben dieser Mann ist es, dessen Tod ein unwiderlegliches Zeugniß ablegt, wie blind und undankbar die Nation handelt, wenn sie einem Gellert ihre ganze Verehrung, alle ihre Klagen widmet, und das größere Verdienst Rabeners, sein vortreffliches Genie und seinen originellern Geist ungepriesen vergißt. ${ }^{39}$
}

Der um Gellert betriebene Totenkult geht vor allem auf den schon genannten Nachruf Einige Züge von Gellerts Charakter (1770) von Christian Daniel Schubart zurück, der Christian Fürchtegott Gellert vorrangig „als Christ und Moralist, als praktizierenden Sittenlehrer“ herausstellt und es, so die Kritik Meyer-Krentlers, bei einer Auflistung seiner literarischen Verdienste bewenden lasse. ${ }^{40}$ Auch die

\section{Ibid., S. 6 .}

34. Id.

35. Ibid., S. 7-10. „[E]in Mann, der ein Weiser, ein Christ, ein Genie, ein guter Bürger, ein Mentor so manches Telemachs war, ---- der Unschuld, Wohlwollen, Menschenliebe, seinen Scherz, Tugend und Patriotismus mit allen Vorzügen verband: ---- Wer kann einen solchen Mann würdig schildern?“ (Ibid., S. 9 f.).

36. „Alles was hier lesen kann, liest und bewundert Sie, und mein Exemplar ist aus einer Hand in die andere gewandert.“ Christian Felix Weiße (Hrsg.), Freundschaftliche Briefe, Leipzig, 1772, S. 190.

37. Anonym [Friedrich Gottlieb Klopstock], Oden und Elegien, An des Dichters Freunde [Wingolf] (1747), Darmstadt, 1771, S. 114-125.

38. Charles Batteux / Karl Wilhelm Ramler (Hrsg.), Einleitung in die schönen Wissenschaften, Bd. 3, 1774, S. 225.

39. Anonym, Ueber den Werth einiger Deutschen Dichter, S. 296.

40. Meyer-Krentler, Gellert und Gellerts Legende, S. 231. „Einen besonders anschaulichen Eindruck von der lediglich in zweiter Linie ästhetischen Beurteilung der Werke des Verstorbenen durch die 
akademischen Zuhörer, die sich mit dem verstorbenen Gellert auseinandersetzen, preisen „ausschließlich die praktische, ethische und religiöse Wirkung, die sowohl vom Vortrag des Professors selbst als auch von der bezwingenden moralischen Autorität seiner Person und deren kathartisierenden Charisma ausgegangen sei.“41 Zum Auftakt der mit „die Verfasser“ unterzeichneten Vorrede zu den Schwäbischen Beyträgen zu Gellerts Epicedien heißt es:

Die Menge der kleinen Schriften, welche auf Gellerts Tod herausgekommen sind, haben Deutschland fast wie eine Sündfluth überschwemmt. [...] Man weiß in Schwaben Gellerts Verdienste nicht nur zu schätzen; sondern man fühlt auch seinen Tod, weil seine Schriften von beyderley Geschlecht, wo nicht überall [...], doch an den meisten Orten mit Vergnügen und Nutzen gelesen werden. ${ }^{42}$

Goethe berichtet zwar von einigen Spöttern, die die Gellert'sche „weiche und wie sie glaubten entnervende Manier uns verdächtig zu machen wußten“, lobt aber seine Schriften und die als Gunst empfundene Teilnahme an seinen Vorträgen:

Gellerts Schriften waren so lange Zeit schon das Fundament der deutschen sittlichen Kultur und Jedermann wünschte sehnlich, jenes Werk gedruckt zu sehen, und da dieses nur nach des guten Mannes Todes geschehen sollte, so hielt man sich sehr glücklich, es bei seinem Leben von ihm selbst vortragen zu hören. Das philosophische Auditorium war in solchen Stunden gedrängt voll, und die schöne Seele, der reine Wille, die Teilnahme des edlen Mannes an unserem Wohl, seine Ermahnungen, Warnungen und Bitten, in einem etwas hohlen und traurigen Ton vorgebracht, machten wohl einen augenblicklichen Eindruck; allein er hielt nicht lange nach [...]. ${ }^{43}$

\section{Der durchaus noch differenzierten, auf Rabener bezogenen Kritik in Dichtung und Wahrheit:}

Die Art, wie dieser Schriftsteller [Gottlieb Wilhelm Rabener] seine Gegenstände behandelt, hat wenig Ästhetisches. [...] Was er aber und wie er es auch vorbringt zeugt von seiner Redlichkeit, Heiterkeit und Gleichmütigkeit, wodurch wir uns immer eingenommen fühlen; der unbegrenzte Beifall seiner Zeit war eine Folge solcher sittlichen Vorzüge ${ }^{44}$

unmittelbare Nachwelt vermittelt ein anonymer Text in den von dem Lyriker, Publizisten und Ludwigsburger Musikdirektor Christian Daniel Friedrich Schubart (1739-1791) herausgegebenen Schwäbische[n] Beyträge[n] zu Gellerts Epicedien. Der Autor der prosaischen Würdigung, die charakteristischer Weise den Titel Einige Züge von Gellerts Charakter trägt und demgemäß vor allem auf die moralische und religiöse Integrität und die Vorbildfunktion des Verblichenen abstellt, ließ darin auch dessen wichtigste Buchveröffentlichungen vor den geistigen Augen der Rezipienten samt kurzen Bewertungen Revue passieren.“ (Bogner, „Gellert oder: Der Nachruf“ S. 255-302; hier S. 264 f.).

41. Vgl. Bogner, ibid., S. 264.

42. Christian Friedrich Daniel Schubart (Hrsg.), Schwäbische Beyträge zu Gellerts Epicedien, ohne Seitenzählung (A2, A4).

43. Johann Wolfgang von Goethe, Aus meinem Leben. Dichtung und Wahrheit. Zweiter Theil. Siebentes Buch, in ders., Sämtliche Werke, hrsg. von Klaus Detlef Müller, Frankfurt a. Main, Suhrkamp, Bibliothek deutscher Klassiker, 1986, 1. Abt. Bd. 14, S. 322.

44. Ibid., S. 286. „In den äußeren Formen ist er zwar mannichfaltig genug, aber durchaus bedient er sich der direkten Ironie zu viel, daß er nämlich das Tadelnswürdige lobt und das Lobenswürdige tadelt, welches rednerische Mittel nur höchst selten angewendet werden sollte; denn auf die Dauer fällt es einsichtigen Menschen verdrießlich, die schwachen macht es irre, und behagt freilich der großen Mittelclasse, welche, ohne besondern Geistesaufwand, sich klüger dünken kann als andere. Was er aber und wie er es auch vorbringt, zeugt von seiner Rechtlichkeit, Heiterkeit und 
folgt dann zunehmend undifferenzierter und abwertend spätere literaturwissenschaftliche Kritik, mit der an Goethes Kritik anknüpfend auch Rabener eine poetisch minderwertige Qualität und ein seichtes geistiges Anspruchsniveau zugeschrieben wird, das zu Selbstüberschätzung und Überheblichkeit einladen würde. In der Literaturgeschichtsschreibung des 19. Jahrhunderts wird Rabener immerhin noch zugestanden, grundsätzlich für die gesamte sittliche und geistige Volksbildung von unermeßlicher Bedeutung geworden zu sein. Dieses Verdienst wird vor allem auf die aus seiner Dichtung sprechende Natürlichkeit seiner Person, das ihm seit Schiller zugesprochene Naive seiner Dichtung, zugesprochen: „Aus jeder Zeile sprach die offene harmlose, heitere, liebenswürdige Natur, die unwiderstehlich anzog und sittlich erhob und kräftigte, auch wenn sie züchtigte.“ 45

Durch die Darstellung des Mittelstandes und die dadurch erreichte allgemeine Schärfung des Bewusstseins für das Lächerliche im gesellschaftlichen Leben habe er, im Gegensatz zu den Genies, den einzig möglichen Weg für die „weitere Entwicklung und geistige Bildung des deutschen Volkes [...] in höchst befriedigender Weise erfüllt" ${ }^{46}$. Abgesehen von der darin liegenden Unterschätzung sowohl der Person Rabeners als auch der Substanz seiner Satirischen Schriften, die lediglich an der Oberfläche harmlos heiter scheinen, kommt hier aber vor allem die grundsätzliche Wertschätzung und Anziehungskraft seiner Person wie die seines publikumswirksamen Werks zum Ausdruck. Im 20. Jahrhundert wird Rabener aber dann in Verkennung der subtilen Ironie und komplexen formalen wie inhaltlichen Gestaltung auch Konzeptlosigkeit und grobschlächtige Bosheit (Kühne 1914) ${ }^{47}$ vorgeworfen, in Ignoranz des historischpolitischen Kontextes mangelnde Couragiertheit in Form einer „hasenherzige[n] sächsische[n] Satire“48 (Köster 1925) und dass er als „Volksschriftsteller“ mit

Gleichmüthigkeit, wodurch wir uns immer eingenommen fühlen; der unbegränzte Beifall seiner Zeit war eine Folge solcher sittlichen Vorzüge. / Daß man zu seinen allgemeinen Schilderungen Musterbilder suchte und fand, war natürlich; daß einzelne sich über ihn beschwerten, folgte daraus; seine allzulangen Vertheidigungen, daß seine Satire keine persönliche sei, zeugen von dem Verdruß, den man ihm erregt hat. Einige seiner Briefe setzen ihm als Menschen und Schriftsteller den Kranz auf.“ (Ibid., S. 75 f.).

45. Hermann Hettner, Geschichte der deutschen Literatur des 18. Jahrhunderts, Braunschweig, Vieweg, 1872, S. 395-400.

46. Heinrich Kurz, Geschichte der deutschen Literatur, Leipzig, Teubner, 1869-70, Bd. 2, S. 658 f., hier 659.

47. Seine ,inneren Kunstmittel ' betreffend liege das Anziehende und Charakteristische von Rabeners Satiren in seiner Konzept- und Ziellosigkeit, die sich gegen alles wende, was ihm in den Weg komme und „dem Überraschenden seiner Gedankenverbindungen“, die das „eigentümlich sprunghafte seines Stils“, und das ,Witzige“ ausmachen. Auf die Dauer wirke seine Lektüre jedoch „unbefriedigend und abstoßend [...]: es ist kein Genuß, immer wieder Bestechlichkeit, Unwissenheit, Gemeinheit, und besonders Ungebildetheit und Rohheit breit ausführlich beschrieben zu sehen." (Karl Kühne, Studien über den Moralsatiriker Gottlieb Wilhelm Rabener, 1740-1755, InauguralDissertation Friedrich-Wilhelms-Universität zu Berlin, Neustrelitz 1914, S. 86).

48. „Klopstock hat Rabener als den ,allzeit Gerechten“ gerühmt. Das kann man unterschreiben, wenn man jene halbherzige Gerechtigkeit im Auge hat, die zu dem Ergebnis gelangt, dass überall etwas auszusetzen sei und hüben wie drüben gesündigt werde. Forderte man aber jene höhere 
der Wahl und Einkleidung seiner „moralisch-didaktischen Gedanken“ nur „ein (mehr oder minder sensationslüsternes, schadenfrohes, amüsiertes und erst zuletzt lernbegieriges) Publikum“ bediene, so dass seine Satiren als aliterarische Geschmackslosigkeit zu werten seien, die „Redlichkeit und lautere Gesinnung“ nicht zu kompensieren vermögen (Biergann 1961) ${ }^{49}$. Gründlich verkannt wird damit die Vielschichtigkeit und differenzierte Gestaltung der zu Lebzeiten wirkmächtigen Schriften Gellerts und Rabeners; schon für die Fabelerzählungen Gellerts gilt, dass diese „meist reichhaltiger [sind], als die dürre und abstrakte Moral vermuten läßt" ${ }^{50}$. In der bereits in Gellerts Fabeln praktizierten und so transportierten Poetologie, so z.B. im Sinnbild der vergnügt von Blüte zu Blüte fliegenden und Honig sammelnden Biene in der Fabel Die Biene und die Henne, zeigt sich eine über die zeitgenössische Theorie hinausweisende und auf Schiller vorausdeutende Autonomie des schöpferisch tätigen Dichters an, durch die dann Gellert eine „soziale Vorrangstellung des Autors begründet“51.

\section{Autorschaft zwischen Poetik und Ökonomomie}

Gellert bezieht sein Einkommen bei bescheidener Lebensführung hauptsächlich aus seinen Vorlesungen als außerordentlicher Professor in Leipzig (100 Taler pro Jahr) sowie durch persönliche Kolloquien und Privatunterricht. „Gellerts Ideal ist jedoch nicht der edle Arme, sondern der gütige Reiche, der seine materiellen Einkünfte sogleich wieder zu karitativen Zwecken verwendet und damit seine ganze Umwelt an seinem Reichtum teilhaben lässt. “52 Auf die für Gellert geltende hohe Bedeutsamkeit des Geldes spielt Rabener aus der Perspektive Wohlhabenden scherzhaft an, wenn er zum Schluss seines Briefs in Rekurs auf den zu Anfang des Briefs an Gellert vom Sommer 1753 gemachten Vorwurf ausbleibender Briefe anmerkt: „Wenigstens werden sie an mich denken, wenn Ihnen ein

Gerechtigkeit, die getragen von einer starken ethischen Überzeugung vor keinen Autoritäten sich duckte, und die mit befreiendem Lachen weder hoch noch niedrig schonte, dann versagte Rabener und die ganze hasenherzige sächsische Satire völlig [...], ihr fehlte der tiefe sittliche Ernst, das Pathos und der strafende Zorn (den Klopstock bei Rabener so einvernehmlich besingt!), der lachende Hohn und auch die beherrschende Phantasie, die aus dem Vielzuviel erst ein Weltbild schafft. Sie hütete sich, irgend etwas Hohes, die Religion, den Hof, die Obrigkeit anzutasten, und hielt sich immer in mittlerer Sphäre, indem sie die bekannten Thoren [...] durchhechelte.“ (Albert Köster, Die deutsche Literatur der Aufklärungszeit, Heidelberg, Winter, 1925, S. 68).

49. Die „meisten Rabner'schen Schriften [sind] heute im eigentlichen Sinn ,abgeschmackt $[$ [...]: d.h. ohne Geschmack, weil ohne Salz und Würze.“ Von einer „brilliant komponierten und geschriebenen allgemeinen Satire [...] kann ja bei Rabener keine Rede sein; sein technisches Können, seine stilistische und formale Kraft reichten nicht aus, um seine Schriften über sein Jahrhundert hinweg zu retten. Redlichkeit und lautere Gesinnung allein vermögen nicht, einem Werk das Siegel der literarischen Unsterblichkeit aufzuprägen.“ (Armin Biergann, Gottlieb Wilhelm Rabeners Satiren, Phil. Diss. Universität zu Köln, 1961, S. 30 und 80).

50. Witte, „,Die Wahrheit durch ein Bild zu sagen: Gellert als Fabeldichter“, in ders., Ein Lehrer der ganzen Nation, S. 31.

51. Ibid., S. 32.

52. Werner Jung, „Das Geld und die guten Worte. Zur Rolle des Geldes bei Gellert“, in Witte, Ein Lehrer der ganzen Nation, S. 134-150; hier S. 136. 
Accisgroschen [Lebensmittelsteuer] zum Merseburger [Bier] fehlt. Leben Sie wohl mein Stummer! / Rabener.“ ${ }^{33}$ Den Stellenwert einer für Gellerts gesundheitliches Wohlbefınden unerlässlichen existentiellen Grundsicherheit macht Rabener auch in seinem späteren Brief vom 18. Januar 1757 deutlich, wenn er in Bezug auf Ihre Besoldung anmerkt:

\begin{abstract}
Was machen Sie, mein guter bester Gellert? Elegien? Hum! Ein Philosoph wie Sie, wäre sehr unexemplarisch, wenn er sich die gegenwärtige Noth zu sehr niederschlagen lies. Aber, gesund sind Sie doch gewiß? Das will ich Ihnen rathen, denn ich bin sehr gesund, und kann es nicht leiden, daß meine Freunde krank sind. Man versichert mich, daß der König Befehl gegeben habe, Ihnen Ihre Pension richtig auszuzalen. Wie gros kam mir der Feind, der König von Preußen, in dem Augenblicke vor, als ich dieses hörte. Vor Vergnügen vergas ich, daß er mir selbst meine Besoldung zurücke halten läßt. ${ }^{54}$
\end{abstract}

Rabener macht dann folgend unmissverständlich deutlich, dass es ein Gerücht sei, wenn es heiße, dass er in preußische Dienste gehe: „Ich würde es am wenigsten ietzt thun, da ein solcher Entschluß mehr eine Desertion, als eine erlaubte Verbeßerung meiner Glücksumstände, scheinen würde.“ ${ }^{55}$ Eine dann in den unautorisierten Nachdrucken von 1761 gegenüber dem Originalbrief stark modifiziert kursierende Version:

Ich bin muthig, wenn es mir einfällt, daß ich zum Besten meiner Muttersprache diesem König den deutschen Witz predigen soll. Aber ich weiß es schon: Ich predige Brandenburgern ein Aergerniß, und den Franzoßen eine Thorheit, ${ }^{56}$

verkehrt mit dem Einschub „dem tapfersten und noch nicht überwundenen Könige dieser Zeit (ach wäre dieser König nur unser Freund.)“ und dem Wegfall der Passage „Aber ich weiß schon [...]“ Rabeners Einstellung gegenüber Friedrich geradezu ins Gegenteil.

Bei bescheidenem Lebensstil und anderer materieller Lebensgrundlage verkennt Gellert nicht die Realität eines sich aktuell im deutschen Literaturfeld durchsetzenden Schreibens für den Markt im Takt der Messen. Er befindet sich damit als Autor an der Schwelle zur einer auch ökonomisch verstandenen Autorschaft. Die Produktionsseite im Blick behaltend verschließt sich Gellert somit nicht der Thematik einer grundsätzlich einzufordernden Bezahlung schriftstellerischer Leistungen - was er allerdings nicht offen proklamiert, sondern pointiert in satirischer Zuspitzung wie gleichzeitiger Relativierung präsentiert, so

53. Rabener an Gellert, Brief vom [Sommer] 1753, in Gottlieb Wilhelm Rabener, Briefwechsel und Gespräche, hrsg. von E. Theodor Voss, Göttingen, Wallstein, 2012, Nr. 137, S. 207 f. sowie in C.F. Gellert, Briefwechsel, hrsg. von John F. Reynolds, Bd. 1 (1740-1755), Berlin/New York, de Gruyter, 1983, S. 153 f., hier S. 154.

54. Rabener an Gellert, Brief vom 18. Jenner 1757, in Rabener, Briefwechsel und Gespräche, Bd. 1, Nr. 203. Voss gibt hier wie er betont „erstmals“ die „authentische Fassung des bekannten Briefs, der zu den illegal gedruckten Briefen Rabeners und Gellerts gehört“ wieder (Dresdener Abschrift h1). Reynolds Wiedergabe der Münchener Fassung h2 „hingegen stimmt bis auf wenige Stellen mit den (untereinander weitgehend identischen) illegalen Drucken überein“ (Rabener, Briefwechsel und Gespräche, Bd. 2, Kommentar zu Nr. 203, S. 117).

55. Ibid. Kommentar zu Nr. 203, S. 117.

56. Id. 
im Vierzehnten Brief. An den Herrn Sekretär $K^{* *}$ seines Briefstellers Praktische Abhandlung von dem guten Geschmacke in Briefen (1751), in dem deutlich wird, dass letztendlich die Verleger profitieren, die den Druck und damit Setzer und Buchführer bezahlen müssen, damit diese ihren Lebensunterhalt bestreiten können, aber offenbar nicht der irdischen Dingen enthobene Autor:

\begin{abstract}
Sehen Sie wohl? Ein rechter deutscher Autor muß keine Oster- oder Michaelismesse vorbey lassen, ohne etwas daraus zu geben, wenn es auch nur ein Werk von zween Bogen wäre. Nein, nein, ich lasse mir mein Recht nicht nehmen. Wovon sollten die Setzer und Buchführer leben, wenn der Autor nicht schreiben wollte? Und was sollte der Autor anfangen, wenn er nicht von Messe zu Messe schreiben könnte? Nein, nein, ich lasse mir mein Recht nicht nehmen, ich schreibe, so lange ich gesunde Hände habe. ${ }^{57}$
\end{abstract}

Durch die funktionsspezifische personale Zuordnung des ökonomischen Gewinns am Buchmarkt wird der vielschreibende Autor hier nicht (nur) wie sonst üblich (so auch bei Rabener) mittels satirischer Überzeichnung hinsichtlich seiner Produktion dichterisch minderwertiger Masse in den Blick genommen, sondern der Akzent der hier deutlich gemachten Kritik liegt bei der übertriebenen Selbstlosigkeit des Autors sowie seiner Interessenfixierung auf die Schreibtätigkeit, bei der der Autor sich selbst den betreffend aktiv vom materiellen Verdienst bzw. Gewinn an seiner (maßlosen) Produktivität ausschließt. Wenn es weiter heißt,

\begin{abstract}
Es ist gar zu hübsch, wenn man sich im Meßcatalogo, bald darauf in den Zeitungen und in den Journalen, und endlich in den Händen der Welt sieht. Ich komme selten zu jemanden, daß ich nicht für meinen Fleiß belohnt werde, und wenigstens eine von meinen Schriften auf dem Fenster, oder auf dem Nachttische, ganz sauber eingebunden finde. Ich eile nach Hause, und nehme die Feder in die Hände, und schreibe, was ich schreiben kann, und stelle mir schon einen neuen Ort vor, wo ich mich wieder finden werde, wenn es auch schon in den Händen eines Holzbauers seyn sollte, ${ }^{58}$
\end{abstract}

thematisiert Gellert grundsätzlich subjektgebundenes Autoren(selbst)bewusstsein, überzeichnet diesen Autoren-,Stolz“ aber - einen gängigen Topos aufgreifend - durch die damit verbundene, an Eitelkeit grenzende und die aktuelle, mediale Vielfalt - Messkataloge, Zeitungen, Journale - ausreizende Spiegelung in der materiellen Präsenz des Gedruckten. Aus dem dann folgenden „merkwürdigen Histörchen“ einer faktischen Begegnung mit einem Holzbauern, der den Buchhändler als faktischen Empfänger barer Münze für den Autor aller von ihm angepriesenen Bücher hält, wird deutlich, dass Gellert indirekt deutlich macht, dass diese materielle Gegenleistung schon aus der Perspektive eines einfachen Holzbauers den Autoren selbst zusteht - und nicht (nur), wie in der Praxis des Handel üblich, den Buchhändlern (Druckern und Verlegern).

Die Autorenthematik nimmt er erneut im Sechs und vierzigsten Brief. An den Herrn Sekretär K. in der Überzeichnung selbstironisch anmutender ökonomischer Ausreizung des Bescheidenheitstopos auf:

57. Christian Fürchtegott Gellert, Gesammelte Schriften, hrsg. von Bernd Witte, Bd. 4, Berlin/ New York, de Gruyter, 1989, S. 168. Vgl. ebenso Gellert an Moritz Ludwig Kersten, Brief vom 25. Oktober 1748, in C.F. Gellert, Briefwechsel, Bd. 1, S. 25-28.

58. Gellert, Gesammelte Schriften, Bd. 4, S. 168. 
Sie sehen wohl, wenn man einen Autor zum Freunde hat: so ist man keine Stunde sicher, daß er uns nicht ein Buch dediciert, oder uns doch mit einem beschenkt, wir mögen es wollen oder nicht. [...]; ich schicke ihnen dieses Buch dennoch, und bilde mir in meiner Ruhe fest ein, daß sie es mit Vergnügen lesen werden. Mit diesem unverschämten Irrthume muß sich ein Autor für seine Mühe bezahlt machen; und je weniger ihm die Welt Beyfall geben will, destomehr muß er sich den seinigen geben. ${ }^{59}$

Er stilisiert sich so selbst zum „furchtbare[n] Scribenten“, der schon zu Schulzeiten alles in Verse gebracht habe, die er als „Vorausdeutungen von der Autorschaft“ auslegt habe, wobei er den Sekretär als Jugendfreund und ehemaligen Dichterverbündeten einbindet (und ihn damit aber auch in die Reihe elender Scribenten aufnimmt) - „Ich wollte das ich das itzund wäre, was wir uns damals zu seyn einbildeten“. Dieses neue alte Bündnis nimmt er dann zum Anlass einer stellvertretenden Bittstellung bei ihm als „Freund“, um für ihn stellvertretend bei „dem Herrn Grafen“ zu ersuchen, „seine Gnade zu erhalten, und [s]ein Glück seiner Vorsorge zu empfehlen“. Für dieses Ersuchen gibt er sich selbst als „zu verschämt, die Zahl der Supplicanten zu vermehren, und einen großen Herrn mit meinen Angelegenheiten zu beschweren“ aus. ${ }^{60}$ Zur Sprache kommt bei aller satirischer Übernahme gängiger Topoi und der inszenierten Selbstbloßstellung des elenden Scribenten und seines stark begrenzten Verständnisses von Autorschaft dennoch ein wahrer Kern eines doch auch allgemeingültigen Autoren-Schicksals: Im Falle mangelnder oder inadäquater materieller und ideeller Anerkennung durch den Markt bzw. das Publikum sind die Autoren in trostspendender Anerkennung auf sich selbst und ihre Einbildungskraft zurückgeworfen; so heißt es nicht erst im Briefsteller, sondern bereits in Gellerts Brief an Kersten vom 15. März 1748: „Mit diesem unverschämten, doch süßen Irrthume muß sich ein Autor für seine Mühe bezahlt machen."61

Witte stellte bereits 1989 heraus, dass es Gellert in seinem Briefsteller „gar nicht mehr darum geht, Musterbriefe für bestimmte lebenspraktische Situationen zur Verfügung zu stellen“, sondern diese „als literarische Kompositionsform“ und „als ein in sich geschlossenes Ganzes“ zu verstehen sind - als „Ausdruck eines Individuums“, nämlich des Autors Gellert selbst; „durch das Schreiben von Briefen [konstituiere sich] in der Ausnahmeexistenz des Schriftstellers ein neuzeitliches, das heißt aus den traditionellen Bindungen an den Feudalstaat und an die Kirche befreites Individuum. "62 Damit nimmt Gellert eine Schlüsselstellung in der Entwicklung modernen Autorenbewusstseins ein. Von Gellerts Selbstbewusstsein - als ein zum Autor und nicht zum Amt Berufener - zeugt auch der Brief an Borchwart vom 21. Dezember 1751, in dem sich Gellert selbst als Genie bezeichnet, dem seine amtlichen Verpflichtungen entgegen stehen:

59. Ibid., S. $197 \mathrm{f}$.

60. Ibid., S. 198.

61. C.F. Gellert, Briefwechsel, hrsg. von John F. Reynolds, Bd. 1 (1740-1755), Berlin/New York, de Gruyter, 1983, S. 24.

62. Witte, „Die Individualität des Autors. Gellerts Briefsteller als Roman eines Schreibenden“, in The German Quarterly, Bd. 62, 1989, S. 5-14; hier 5 f. 
Warum hat man mir ein öffentliches Amt gegeben? Ich habe es zum voraus gewußt, daß das Amt den Autor verdrängen würde; denn ich bin ein Genie, das eine einzige gemeßene Beschäftigung zu den andern ungeschickt gemacht wird. ${ }^{63}$

Dem entsprechend proklamiert er auch in seinen Vorlesung Wie weit sich der Nutzen der Regeln in der Beredsamkeit der Poesie erstreckt das Genie zur notwendigen Voraussetzung und „erste[n] Regel der Poesie“:

Man kann ihre [der Dichtkunst] Hauptregeln wissen und ausüben, und dennoch das elendste Werk hervorbringen. Wie glücklich wären wir, wenn wir hiervon weniger Zeugen aufzustellen hätten; wenn es nicht so wahr wäre, daß die erste Regel der Poesie diese sey: Man muß Genie haben! ${ }^{64}$

Diesem Bewusstsein Gellerts entgegen steht ein spätestens mit der Rezeption Goethes und Schillers Gemeinplatz werdender Vorwurf niedrigen dichterischen Niveaus, als dessen Folge Rabener wie Gellert zu Gegenbildern einer nicht erstrebenswerten Form der Autorschaft stilisiert werden und schließlich zu Topoi in Vergessenheit geratener Dichter degenerieren, so in Jean Pauls Wunderbarer Gesellschaft wo der erfolgs-und publikumsorientierte Schreiber sich fürchtet, wie ein „zweiter Gellert, der bloß glatten und matten Leipzigern gefallen will“65, zu enden. Der Grund für das rasche Vergessen ihrer zu Lebzeiten so berühmten Schriften ist also vor allem in der posthumen Rezeptionsgeschichte ihrer Werke zu suchen, die mehr den Vorbildcharakter ihrer Person sowie ihre Leistungen in der Volkserziehung herausstellt und ihren Werken einen poetischen Gehalt nachhaltig abspricht - wie am Beispiel Mauvillon/ Unzer gezeigt, die den Erfolg Gellerts und Rabeners auch grundsätzlich einer „Zeit, da die Literatur noch nicht ausgebreitet war“, zuschreiben.

\section{Ein kleines Stückchen aus der Nachwelt - Rabener über den fließenden Gellert und den spitzigen Rabener}

Rabener selbst sieht einen Grund seines Erfolgs - so zumindest die offizielle Erklärung in der Vorrede zu seinen Satyrischen Schriften - in der sich in seiner allgemeinen, also persönliche Angriffe vermeidenden Satire ausdrückenden Liebe zu seinen vernünftigen Mitbürgern, weswegen der Satiriker „ein Recht erhält, auf sein redliches Herz stolz zu sein." ${ }^{66}$ Dem dennoch stark ausgeprägten lebensweltlichen Bezug, mit dem er "die Thorheiten nach dem Leben“ zeichne, verdanke er nicht zuletzt auch seinen Erfolg beim Publikum. ${ }^{67}$ Die Schlüsselstellung von Vorreden und Vorworten für die Selbstdarstellung von

63. Gellert, Briefwechsel, Bd. 1, S. 99.

64. Gellert, Gesammelte Schriften, Bd. 5, S. 203.

65. Jean Paul Richter, „Die wunderbare Gesellschaft in der Neujahrsnacht“, in ders., Sämtliche Werke, hrsg. von Norbert Miller Abt. 1, Bd. 4, Kleinere erzählende Schriften 1796-1801, München, Carl Hanser Verlag, 1962, S. 1121-1138, hier 1128 f.

66. Rabener, „Vorbericht“, in ders., Sammlung Satyrischer Schriften, Bd. 1, Theil 1, Leipzig, Dyck, 1751, S. 118. „Eine allgemeine Satyre bleibt der Nachwelt immer neu.“ (Ibid., S. 41).

67. Ibid., S. 44 ; S. 120. 
Autoren spiegelt Rabener satirisch schon in seinem umfangreichen zehnteiligen Beitrag Der Autor, der in den Belustigungen des Verstandes und Witzes im Jahr 1744 erscheint. In einem als Leserbrief an den „allerliebenswürdigsten Herrn Autor“ gestalteten Beitrag wird das Aussparen der sonst unerläßlichen Vorrede (mit indirektem Rekurs auf ihre Funktion) ausgebreitet. Auch wird hier - ähnlich wie dann später Gellert in seinem Briefsteller - auf die Eitelkeit des Autors und dessen Stellung zur Öffentlichkeit rekurriert, während den Fokus der Kritik des Beitrags aber die gängige Praxis unrechtmäßiger, d.i. nur namentlicher Autorschaft, betrifft, die von Leserseite - im seltenen Fall der Übereinstimmung von faktischer und namentlicher Autorschaft - schon als hinreichendes Kriterium von „wirklicher“ und „wohlverdienter“ Autorschaft gewertet wird sowie auch üblicherweise die Aussagen in Vorreden von den Lesern als Authentizität des Autors fehldeutet werden:

\begin{abstract}
Was aber suchet ein Autor mehr, als daß er von seinem Namen, und von seinen Gedanken eine anschauende Erkenntnis haben könne, um sich recht völlig daran zu vergnügen, und daß andere von ihm sagen und schreiben, er habe sich als Autor öffentlich bewiesen? Nun diese haben Sie erhalten. Sie sind nicht titulär, wie viele angesehene Männer in der Welt, welche zu Ihren Schriften nichts als den Namen hergeben, sondern ein wirklicher Autor. Noch mehr! Sie sind ein wohlverdienter Autor [...]. Sie sind also ein durch sich selbst gewordener Autor. [...] Mein Herr! Sie sind ohne Vorrede ein Autor geworden. Etwas seltenes! ohne Vorrede haben Sie Ihre Absicht entdeckt. Das heißt deutlich und aufrichtig seyn! Die Vorreden sind gleichsam das Antlitz des Autors! [...] Einige Hochweise [die Anhänger der Physiognomielehre Lawaters] unterstehen sich aus dem Gesichte den ganzen Menschen zu beurtheilen: und die können aus einem Blicke in die Vorrede den ganzen Autor kennen lernen.[...] Diese Antlitzwissenschaft und Gesichtswahrsagung wird sogar auch bey den Autoren gebraucht. ${ }^{68}$
\end{abstract}

Die Satyrischen Schriften Rabeners (wie selbst seine als moralisierend empfundenen Vorberichte ebenso wie seine Vor-, Nach- und Zwischenworte) zeigen bei näherer Analyse - insbesondere ihrer Verweisstrukturen auf antike Grundlagentexte und damit implizit-kritisch auch auf politische Hintergründe - eine ihnen lange nicht zuerkannte Komplexität, die im Schatten der grundsätzlich angezweifelten oder abgesprochenen dichterischen Kompetenz Rabeners wie Gellerts verkannt wird. ${ }^{69}$ Fast prophetisch mutet dann Rabeners provokant-herausfordernd gemeinte Ausführung einer als gering gemutmaßten Wirkungsgeschichte ihrer Schriften an:

Es werden Tage kommen, wo wir beyde vergessen sind, und in denen wir höchstens darum noch genennet werden, weil wir gelebt haben. "Der fließende Herr Gellert und der spitzige Herr Rabener, (wird es heißen) haben hier und da ganz artige Gedanken gehabt, und die wenigen Bogen, die von ihren vermuthlich gar weitläuftigen Werken noch übrig sind, verrathen einigen Geschmack, so gut man ihn von den unaufgeklärten Zeiten, in denen

68. Anonym [Gottlieb Wilhelm Rabener], Der Autor, Fünftes Stück, Belustigungen des Witzes und Verstandes, Christmonat 1743, S. 497-517, hier S. 498-500.

69. Vgl. dazu Nadja Reinhard, Moral und Ironie bei Gottlieb Wilhelm Rabener. Paratext und Palimpsest in den Satyrischen Schriften, Göttingen, Wallstein, 2013; darin insb.: „Rabeners satirische Schriften - Praxis einer ironischen Ethik“, S. 315-324; sowie „Die implizite moraldidaktische Satire-Theorie der [Antritts-]Rede“, S. 302-310 und „Die Programmatik der Antrittsrede“, S. 310-313. 
sie gelebt haben, erwarten kann etc.» Wie gefällt Ihnen dieses Stückchen aus der Nachwelt, mein lieber Gellert? Ich bin gelassen dabey, wenn diese Nachwelt nur erfährt, daß Sie mein Freund gewesen sind. Will die undankbare Nachwelt meine Schriften nicht lesen, so soll sie doch meine allergnädigsten Befehle lesen, durch die ich mich als Steuersekretär verewige, so, wie ich mich dadurch, und nicht durch den Witz, ernähre. ${ }^{70}$

Einige „ganz artige Gedanken“ ausgenommen stuft Rabener selbstironisch die Wirkung ihrer beider Werke - mit provokantem Unterton gegenüber Gellert, dem mit einer gehörigen Portion Eitelkeit sehr an seinem Ruf und dem Erhalt für die Nachwelt gelegen ist - als wenig nachhaltig und sein beruflichjuristisches Wirken, auch ökonomisch gesehen, als dem Scharfsinn seiner satirischen Schriften überlegen ein. Aus der Perspektive eines ihre Wirkung vorwegnehmenden „Stückchen[s] aus der Nachwelt“ benennt er hier seinen Freund Gellert und sich selbst selbst-ironisch und der Sache nach treffend (aber nicht ganz ihrer Wirkungsgeschichte gemäß) als den fließenden Herrn Gellert und den spitzigen Herrn Rabener:

Das Horaz'sche Aut prodesse volunt aut delectare poetae, das Gellert gattungsgebunden über seine Fabeln ${ }^{71}$ zu erreichen sucht, gelingt Rabener über die konsequent satirische Schreibart, für die er bereits in den Belustigungen als Satireschreiber ersten Ranges gehandelt wird und auf Anerkennung und konstruktive Kritik trifft, die gerade seine gattungsungebundene Vielfalt der formalen Gestaltung seiner Satiren und ihre komplexen Rahmungen (auch als Spiel mit der Vielfalt der Gattungen) würdigen. Rabener selbst spricht anerkennend von dem für ihn bereichernden Nutzen der „vernünftigen Kritiken der Kenner“72, die er auch in seinen Schriften berücksichtigt habe, wie auch vom guten Erfolge seiner Schriften, die er als von öffentlichem Beifall begleitetes „Urtheil der Welt" ${ }^{73}$ wertet. Tatsächlich wird zwar der vor allem für Gellerts Fabeln geltende und von ihm selbst entwickelte Stil natürlichen Erzählens als einer „leichten und fließenden Schreibart“"74 für Gellert charakteristisch, für die er die enge Regelbefolgung poetologischer Vorschriften zugunsten der „Vortrefflichkeit des Genies“75 in ihrer Bedeutsamkeit zurückstellt; er führt aber gerade nicht zu einer historisch-nachhaltigen künstlerischen Würdigung seiner Schriften, zumindest wird der Name Gellert zwar mit einer fließenden Schreibart, nicht aber mit einem genialischen Schreiben in Verbindung gebracht. Auch Rabener betreffend gilt der Nachwelt zwar seine satirische Schreibart als charakteristisch, diese zeichnet sich aber entsprechend der Rezeptionsgeschichte seiner Satirischen Schriften gerade

70. Rabener an Gellert, Dresden 19. Januar 1756 (Rabener, Briefwechsel und Gespräche, Bd. 1, Nr. 178; Gellert, Briefwechsel, Bd. 2, 1987, S. 3 f.).

71. „Eine kurze und auf einen gewissen Gegenstand anspielende Erdichtung, die so eingerichtet ist, da sie zugleich ergötzet und zugleich nutzet, nennt man eine Fabel.“ (Gellert, Schriften zur Theorie, S. 11); Aut prodesse volunt aut delectare poetae (Horaz, Vers 333).

72. Rabener, Vorbericht, S. 4.

73. Ibid. Rabener sagt auch hinsichtlich seines Beitrags Versuch eines deutschen Wörterbuchs in den Neuen Beyträgen zum Vergnügen des Verstandes und Witzes: Ich „war so glücklich, dass dieser by vernünftigen Lesern Beyfall fand.“ (Ibid., S. 111)

74. Witte, „,Die Wahrheit durch ein Bild zu sagen: Gellert als Fabeldichter“, S. 30.

75. Gellert, Schriften zur Theorie, S. 55. 
nicht durch seine ihm noch zu Lebzeiten zugeschriebene Spitzigkeit aus - die Rabeners Ruf als in seiner Schärfe gefürchteter Spottgeist und deutscher Swift ${ }^{76}$ begründet, indem er durch Verstand und Klugheit, d.h. mit Witz,, sowie durchaus auch mit selbstkritisch-ironischen Humor und einer mit ironisch-subtilen, politisch-moralischen Tiefsinn gewürzten Vielschichtigkeit seinem Publikum (und in besonderer und dennoch wohldosierter Schärfe seinen Freunden in Briefen) die Wahrheit sagt - und schreibt statt dessen, wenn überhaupt, als oberflächlich-unterhaltende Belustigung auf nur mäßigem dichterischen Niveau als eine zunehmend dem Vergessen übergebene Volksaufklärung Geschichte.

Aber auch die enge Vertrautheit und die gegenseitige Wertschätzung ihrer Werke wird durch Rabeners liebevolle, aber auch hochironisch aufgeladene Antwort an Gellert in diesem Brief vom 19. Jenner 1756 deutlich:

\begin{abstract}
Sie sind ein Spötter, indem Sie sich über das Glück meiner Schriften, die in B[onau] immer auf dem Nachttische liegen, eifersüchtig stellen. Vermuthlich soll ich Sie, zu Ihrer Beruhigung, daran erinnern, daß Kinder von guter Erziehung Ihre Schriften auswendig lernen müssen, und gern auswendig lernen. Der Beyfall des Pfarrers und seiner häuslichen Tochter ist mir so schmeichelhaft, als der Beyfall einer Excellenz und einer Hofdame. Ich habe immer den seltenen Hochmuth gehabt, zu wünschen, daß meine Satyren das Siegel der Orthodoxie erhalten möchten; und es ist mir immer erfreulich, wenn meine Schriften auch denen gefallen, die den Beruf eben nicht haben, witzig zu seyn. ${ }^{77}$
\end{abstract}

Indem Rabener seine eigene poetologische Leistung und den Beliebtheitsgrad seiner Schriften im Bescheidenheitstopos hinter die seines Freundes rückt und durchaus offen gesteht, dass ihm selbst von unwitzigen Köpfen gelesen zu werden schmeichelt, entgegnet er dem als Spötterei ausgelegten Understatement seines Freundes - dem ironisch gefärbten Anstrich zum Trotz - nicht ohne Stolz und mit versteckter Anspielung auf eine Gellert unterstellte statusorientierte Pflege von Kontakten, wenn er die Gesamtbandbreite seines Zielpublikums zwischen Pfarrer/häuslicher Pfarrerstochter und Exzellenz/Hofdame aufspannt, wo hingegen es Rabener gerade nicht auf den Status seines Publikums, sondern auf die aus seinen Satiren sprechende Geradlinigkeit ankommt, der diesen Selbstanspruch auch noch ironisch als sich erlaubten Hochmut kennzeichnet.

76. „Dies ist unser Schwift, Rabener, er welcher mir die erste Gelegenheit gab, seines Freundes Gellerts Schwäche etwas genauer kennen zu lernen.“ (Anonym, Ueber den Werth einiger Deutschen Dichter, S. 296). Indem hier nicht zwischen dem tatsächlichen nicht zur Veröffentlichung oder für die breite Öffentlichkeit bestimmten Privatbriefwechsel unter Freunden und zur Veröffentlichung bestimmter (fingierter) Briefwechsel unterschieden wird, wird Rabener mutwillig als Lieferant von Angriffsflächen gegen Gellert missbraucht und damit in die Richtung persönlicher Invektiven gerückt.

77. Rabener an Gellert vom 19. Jenner 1756, in Rabener, Briefwechsel und Gespräche, Nr. 178, S. 236; Gellert, Briefwechsel, Bd. 2, S. 13 f. 


\section{Statusdenken und Friedenspolitik - Gellert, Rabener und der Preußenkönig Friedrich}

Dass gerade Gellert Wert auf den Status seines Publikums legt und sich auch in der Rolle des Fürstenerziehers gefällt, zeigt Gellerts umfangreiche im teilöffentlichen Bereich kursierende Korrespondenz, die neben der direkten Kontaktpflege auch die positive Resonanz in adligen Kreisen zu Zwecken der Selbstdarstellung in den Briefen aktiv nutzt, insbesondere die als Höhepunkte seiner Gelehrtenkarriere empfundene Unterredung mit König Friedrich von Preußen (Briefe an Johanna Erdmuth von Schönfeld, Johanna Wilhelmine Biehle, Ernst Samuel Jacob Borchward und Gottlieb Wilhelm Rabener) und die am 29. April 1765 vor dem Kurfürsten von Sachsen gehaltene Vorlesung, die dann ein Jahr später veröffentlicht wird. ${ }^{78}$

Nie werde ich vergessen können, daß der Käyserliche Abgesandte, ein Kenner und Befördrer der Wissenschaften, im Jahre 1759 meine moralischen Vorlesungen, umschlossen von der akademischen Jugend, oft besucht und meinen Vortrag mit lauten Beyfall beehrt hat. ${ }^{79}$

Die Mitteilung seiner Audienz beim Preußenkönig an Johanna von Schönfeld ist eine von Stolz geprägte, rhetorisch durchformte und akzentsetzende Selbstdarstellung, die nicht nur seiner Briefpartnerin, sondern, die Lesepraxis im engen teilöffentlichen Bekanntenkreis einkalkulierend, ihrem Bekanntenkreis ein wohlkalkuliertes Bild vermitteln möchte.

Maßgeblich zu Gellerts und Rabeners Berühmtheit trugen dann aber gerade die 1761 unter dem Titel Sechs Briefe von C. F. Gellert und G. W. Rabener unautorisierte Veröffentlichung von Gellerts Gespräch mit Friedrich II und noch einige andere zum Teil willkürlich modifizierte Briefe von Gellert und Rabener bei, die ihr Bild in der Öffentlichkeit nachhaltig prägen. Gellert reagiert auf die unautorisierte Veröffentlichung ihres Briefwechsels mit aufrichtiger Empörung, der auch Rabener in seinem Vorbericht zu seinen Satyrischen Schriften deutlich und ernsthaft Ausdruck verleiht. ${ }^{80}$ Das in dieser unautorisiert verbreiteten Druckfassung durch sein Gespräch mit Friedrich transportierte Bild Gellerts weicht durch eine andere Schwerpunktsetzung und Ordnung (bzw. besser eine rhetorisch wenig geschickte Unordnung) deutlich von seiner eigenen Selbstdarstellung im Originalbrief ab. Die für die Dramaturgie des Gesprächs wichtige Äußerung ,ich bin ein Original“ steht bereits am Anfang und wird nicht durch die von Bescheidenheit zeugenden Worte „aber darum sage ich noch nicht, daß ich ein gutes Original bin“ ergänzt. Als gute Schriftsteller und Geschichtsschreiber werden Mascov, Cramer und Bossuet benannt, was im

78. Vgl. dazu Sybille Späth, „Gellerts moralische Vorlesungen“, in Witte, Ein Lehrer der ganzen Nation, S. 151-171.

79. Christian Fürchtegott Gellert an Freiherr von Widmann, Brief vom 25.01.1761, in Gellert, Briefwechsel.

80. Eine Bibliographie zu den bei Lebzeiten erschienenen illegalen Drucken liefert Theodor E. Voss, „Kommentar“, in Rabener, Briefwechsel und Gespräche, Bd. 2, Göttingen, Wallstein, 2012, S. $295 \mathrm{f}$. 
Originalbrief nicht der Fall ist, und entgegen einer faktisch nie erfolgten offenen Positionierung Gellerts im Literaturstreit wird in der unautorisierten Version (im Sinne einer angedeuteten persönlichen Invektive gegen Gottsched) dessen Lehrer Pietsch ablehnend namentlich genannt und auch die zentrale Bitte um Frieden erfolgt eher beiläufıg von zahlreichen neu eingeführten vorwiegend literarischen Themen überschattet.

Als das Gespräch dann auf den brisanten Höhepunkt zustrebt, ist die lapidare Äußerung Gellerts: ,Ich bekümmere mich nicht mehr um die alte, als neue Geschichte: Damit wird die in Ansätzen politische und auch pazifistische Haltung im Originalbrief zurückgenommen und zugunsten eines desinteressiert scheinenden, fast rückgratlosen Gellert gewendet, der zwar Frieden möchte, aber einem weiteren Disput ausweicht, indem er Desinteresse an der aktuellen historischen Lage bekundet. ${ }^{81}$

Wenn Gellert den Originalbrief aus nicht genannten Gründen von Johanna von Schönfeld in seine Hände zurückfordert und diesen zum Vertrauensbeweis (eines Zutrauens in ihre Diskretion, die seinen Brief nicht einer ungewünscht breiten Öffentlichkeit zugänglich macht) wieder in ihre Hände aushändigt, kann das durchaus auch als Koketterie Gellerts mit einer drohenden ungewollten Drucklegung gedeutet werden. Laut Arto-Haumacher läuft der sich in sechs Teile bzw. Themen untergliederbare Aufbau seines Briefes sowie die Dialogführung auf einige wesentliche Kernaussagen hinaus: „Gellert sei ein Original, die zweimal geäußerte Bitte um Frieden. Bemerkenswert sind auch die subtilen Anspielungen zur Situation der Autoren oder zu den Kriegsumständen, die in der brieflichen Fassung des Gesprächs stecken.“82 Eine Audienz Rabeners findet nicht statt; ein ausgeprägtes nationales Bewusstsein zeigt Rabener in seiner Empörung bei der Vorstellung, sich von einem Franzosen mit Friedrich dem Großen bekannt machen zu lassen, und in der Bedeutung, die er der deutschen Sprache zumisst. ${ }^{83}$

Muß es denn eben ein Franzose seyn, der mitten in Deutschland einen deutschen Autor mit einem deutschen König bekannt macht? Wahrhaftig, mein lieber Gellert, das thut mir weh. Ich habe mich bey dem Marquis entschuldigen lassen, daß ich nicht geübt gnug sey, Frantzösisch mit ihm, und noch weniger mit dem Könige zu sprechen. ${ }^{84}$

Dass Rabener an letzter Stelle der Informationskette steht und Gellert dort in fast unwillig-beiläufiger Kompaktheit einen pflichtbewussten Abriss auf eine von Rabener eingeforderte Stellungnahme gestaltet, zeigt die durchdachte Gestaltung und Adressatengebundenheit seiner Korrespondenz, bei der die Beiläufigkeit und Vorsicht seiner Eitelkeit und einem vom Freund möglicherweise drohenden

81. Christian Fürchtegott Gellert an Freiherr von Widmann, Brief vom 25.01.1761, in Gellert, Briefwechsel (1760-1763), Bd. 3, 1991, S. 91.

82. Rafael Arto-Haumacher, „Den ausführlichen Inhalt einem Brief anzuvertrauen, würde wenigstens wieder die Klugheit seyn: Das Gespräch Gellerts mit Friedrich II.: briefliche Fassung und unauthorisierte Druckvariante“, in Werner Jung / Sybille Schönborn (Hrsg.), Praeceptor Germaniae. Christian Fürchtegott Gellerts 18. Jahrhundert, Bielefeld, Aisthesis, 2013, S. 79-93; hier S. 86.

83. Vgl. Rabener an Gellert, Brief vom 18. Jenner 1757, in Rabener, Briefwechsel, Nr. 203.

84. Ibid., S. 254. 
Vorwurf Vorschub leisten. ${ }^{85}$ Aus der dort wiedergegebenen Unterredung wurden die friedenspolitische Einstellung Gellerts, seine schlagfertig-mutig-offensive Seite und seine Fürsprache für die deutsche Dichtkunst bzw. die Dichtkunst in deutscher Sprache herausgelesen ${ }^{86}$ Gellerts pazifistische Haltung, bei der er den Schriftsteller als Gegenmodell dem Offizier entgegen hält, geht u.a. auch, wie Witte zeigt, aus den Rittmeister-Briefen seines Briefstellers hervor: „Kann man nicht anders berühmt werden, als wenn man der Liebe zum Leben entsagt [...] Ist es möglich, so vergessen Sie den Lorbeer, den man durch sein Blut erkaufen muß." ${ }^{87}$ Indem Gellert den Schriftsteller in den Briefen an den Rittmeister zum bürgerliche Privatheit propagierenden Antihelden stilisiert, der den ,adligen Kriegsherrn zum Ideal des bürgerlichen Privatlebens überzeug[t]“, erscheint der Schreibende als Kontrastfigur. ${ }^{88}$ Gellerts „Fixierung des Briefschreibens auf Empfindungen der Freundschaft [sind daher] nicht eine Idiosynkrasie des ,rührseligen“ Gellert“, sondern ihr liegt „der bewußte Entschluß zugrunde [...], die Maschinerie des Staates, die sich im Krieg als Tötungsmaschinerie erweist, aus dem literarischen Text auszuschließen.“ Mit dieser Entscheidung wird der Schriftsteller zur bürgerlichen Grenzfigur des adligen Staatsmannes und Offiziers. ${ }^{89}$

Rabeners pazifistische Haltung und seine Verurteilung der Gräueltaten des Krieges lassen sich nicht nur durch seine satirischen Schriften, sondern auch durch seinen Briefwechsel belegen. So bedauert er die Vielzahl unschuldiger Opfer des Krieges und der Kriegswirren. ${ }^{90}$ Angesichts seiner Vaterlandsliebe und seines Engagements für Steuerreformen bezeichnet sich Rabener selbst als einen „patriotischen Don Quixote“. ${ }^{11}$ Seinem Tagebuch lässt sich sein unermüdlicher Eifer entnehmen, der pflichtbewussten Fleiß mit kindlicher Freude verbindet. Die äußersten Grenzen „des menschlichen Witzes und Verstandes“ in der Literatur liegen für Rabener zwischen dem Messkatalog und Homer:

Seit den Abentheuern des Ritters von Mancha ist wohl keine tollere und gefährlichere Krankheit gefunden worden, als die Vaterlandsliebe. Und wie jenem die Ritterbücher seiner Zeit den Kopf verwirrt machten, so will ich durch meine Erfahrung jeden Menschen wohlmeynend warnen, Cato's Lettres und Gordens Tacitus nicht zu lesen, oder wenn er

85. Christian Fürchtegott Gellert an Gottlieb Wilhelm Rabener, Brief vom 05. Februar 1761, in Gellert, Briefwechsel, Bd. 3, S. 99-101.

86. Vgl. Arto-Haumacher, Das Gespräch Gellerts mit Friedrich II., S. 86.

87. Christian Fürchtegott Gellert, Praktische Abhandlung von dem guten Geschmacke in Briefen (1751), in Gesammelte Schriften, hrsg. von Bernd Witte, Bd. 4, Roman, Briefsteller, Berlin/ New York, de Gruyter, 1988.

88. Witte, Die Individualität des Autors, S. 7.

89. Ibid., S. 6.

90. „Das arme Land! Und so viel rechtschaffene Leute, die ohne ihr Verschulden mit unglücklich werden! Wie traurig ist die Aussicht in die Zukunft. [...] Ich war ganz bey Ihnen und vergaß, daß ich in Sachsen, in meinem unglücklichen Vaterlande, mitten unter Feinden saß." (Brief Rabeners an Cramer vom 22. Nov. 1756, in Rabener, Briefwechsel, Nr. 197); vgl. auch die Briefe an Schlegel vom 24. Feb. 1758 (Nr. 294), an Lorchen [Christiana Eleonora Deeling] vom 29. Jan.1757 (Nr. 210) und an Gellert vom 25. März 1757 (Nr. 225).

91. Versuch eines Tagebuchs vom 25. May 1759, in Rabener, Briefwechsel, Nr. 332, 353; vgl. auch Brief Rabener an Cramer vom 22. Nov. 1756, in Rabener, Briefwechsel, Nr. 197. 
ja verwegen genug ist, darinne zu lesen, sogleich zum Niederschlagen der aufwallenden patriotischen Hitze, eine Seite vom Staatskalender auswendig zu lernen. Verzeihen Sie mir es wohl, meine gute Freundinn, daß ich so ein Steuerpedante bin, Sie mit Sachen zu unterhalten, welche kaum der Erbmarschall anzuhören genug Geduld haben würde? Aber Sie verzeihen es mir gewiß, ich kenne Sie zu gut, und bey dem glücklichen Vorsatze, den Sie haben, Ihre Kenntnisse in allen Sachen zu erweitern, muß es Ihnen einerley seyn, ob Sie ein Buch aus dem Homer, oder einen Meßkatalogus lesen. Und mich dünkt, diese beyde Sachen sind die äußersten Gränzen des menschlichen Witzes und Verstandes. ${ }^{92}$

\section{Produktive Werkkritik - Rabener liest Gellert}

Wenn Gottsched in seiner Critischen Dichtkunst Rudolph Ludwig von Canitz empfiehlt, zielt seine Empfehlung auf sein Dichterleben sowie seine werkgeschichtlichen Kontinuität und die in seiner Satire Von der Poesie thematisierte Verbindung von einem poetischen Naturel - das auch Gellert mit seinem natürlichen Schreibstil proklamiert - mit der Vorsicht und Sorgfalt eines Staatsbeamten - für die als Jurist und vir bonus Gottlieb Wilhelm Rabener wohl wie kaum ein anderer seiner Zeit einsteht. Wenn Johann Peter Uz an Johann Wilhelm Ludwig Gleim seine Oden mit der Bitte, dieselben „scharf, umständlich und aufrichtig [zu] beurtheilen“ schickt und den Weg zur Vollkommenheit betreffend auf das "große Exempel des Herrn Hagedorn“ verweist ${ }^{93}$, zeugt diese selbstkritische Haltung von Uz nicht nur von seinem dichterischen Selbstverständnis sondern zugleich vor allem von seinem Konzept zur eigenen Positionierung im literarischen Feld der Zeit. Poesie wird hier, so Steffen Martus, als Ergebnis eines generischen Prozesses, als dem zeitlichen Wandel unterliegendes Produkt einer künstlerischen Entwicklung begriffen, die parallel zur biologisch-geistigen Entwicklung des Künstlers verläuft und so die Korrektur sowie ggf. das Verstoßen ,ungerathener (d.h. als Jugendsünden verstandener) Kinder zur vorausschauenden Steuerung des eigenen Werkkorpus mit dem Blick auf die Nachwelt legitimiert.

So übernimmt z.B. Rabener zahlreiche in den Belustigungen anonym veröffentlichte satirische Beiträge in seine Satyrischen Schriften, aber ganz explizit nicht alle. Mit der Prozesshaftigkeit dichterischen Schaffens geht notwendig eine Imperfektibilität des jeweils veröffentlichten bzw. der Öffentlichkeit oder Teilöffentlichkeit bekannt gemachten künstlerischen Produktes einher; dieser Mangel wird aber zu einer qualitativen Auszeichnung des Produktes umgewertet und ein der Zeit unterliegenden und daher ein mit ihrem Fortschreiten gesteigerter dichterischer Anspruch proklamiert. Als Kommunikation einer nie endenden und in diesem Sinne unendlichen auf Natürlichkeit und Vernunft bedachten Zeitinvestition nach dem „Schema von Absage, Übernahme, Korrektur“94, die

92. Versuch eines Tagebuchs vom 25. May 1759, in Rabener, Briefwechsel, Nr. 332, S. 354.

93. Johann Peter Uz an Johann Wilhelm Ludwig Gleim, Brief vom 17.02.1744, in dies., Briefwechsel, hrsg. von Carl Schüddekopf, Tübingen, Bibliothek des lit. Vereins, 1899, S. 46.

94. Steffen Martus, «Die Entstehung von Tiefsinn im 18. Jahrhundert. Zur Temporalisierung der Poesie in der Verbesserungsästhetik bei Hagedorn, Gellert und Wieland", in DVJS 1, 2000, S. 27-43, hier 31 . 
die Wertigkeit des eigenen Werks steigert und von der (vermeintlich) weniger zeitintensiven, unnatürlichen bzw. unvernünftigen Dichtung, insbesondere der Gebrauchsdichtung, abgrenzt, werden die Korrekturen des eigenen Werks zum Zeugnis stetig-unermüdlichen Bemühens um Perfektibilität sowie im so kommunizierten Bewusstsein der eigenen Grenzen zur Demonstration der eigenen Bescheidenheit und fallen damit auf die Person des Autors selbst zurück. ${ }^{95}$

Auf der Basis der Kommunikation seines geistigen wie realen Lebens, als auto(r)biographische Konstruktion, die das Verständnis seiner Texte maßgeblich steuert und rezeptiv mitbestimmt, steht schlussendlich der Autor als Person - auf den der Leser vertraut, bzw. den er kritisiert - für die Qualität seines Werks ein. In diesem Sinne kann der enge Austausch Rabeners und Gellerts verstanden werden, bei dem Gellert sich von Rabener kritische Stellungnahmen einholt. Rabener ermuntert Gellert, seine Lehrgedichte auszuarbeiten und seine Sammlung von Briefen als Musterbeispiele zum Druck zu veranlassen. Rabener ist es auch, der Gellert 1751 überzeugte, die außerordentliche Professur für Philosophie am Dresdener Hof anzunehmen. ${ }^{96}$ Gellerts Roman Die Schwedische Gräfin von $G^{*}$ überzeugt Rabener hingegen dichterisch nicht: „Je, ja! das Buch ist ganz gut, es steht auch nichts ärgerliches drinne, daß es also eine Prinzessinn ganz wohl lesen mag. “97 Auf Gellerts Zusendung seines Bandes Erzählungen und Lehrgedichte rät ihm Rabener, sich aufgrund seines Geschicks noch mehr mit moralisierenden Gedichten zu befassen, während er an einigen anderen Gedichten und Erzählungen wenig Innovation und mangelnde Eindeutigkeit der Erzählweise kritisiert. Sein Gedicht An den Grafen Hans Moritz Brühl bey seinem Vierzigsten Geburtstage mache auf Rabener den Eindruck, als habe Gellert etwas [nicht Rühmliches?] vergessen und verlangt den Einschub einer weiteren Strophe. Gellerts Geistliche Lieder und Oden finden hingegen Rabeners enthusiastische Zustimmung; sie würden ohne Zweifel zur Erbauung der Menschen beitragen, zumal er die Leser über seine Fabeln und Lehrgedichte bereits auf ,erhabene Gedanken" vorbereitet habe:

Sie haben Ihn ganz diesen Beyfall, den Ihnen keiner von Ihren Lesern versagen wird, welcher nicht so unglücklich ist, ein Feind von Religion und Witze zu seyn. [...] Die Erbauung wird doppelt seyn, da die Welt Sie bereits auf einer so vortheilhaften Seite kennt. [...] Wie vortheilhaft wird nunmehr dieses Zutrauen der Welt für unsre heilige Religion seyn ! Ihre Fabeln und Lehrgedichte haben die Leser zu denen erhabenen Gedanken vorbereitet, die sie nunmehr in Ihren geistlichen Liedern finden. Verehrer der Religion werden mit diesen Gedichten den Leichtsinn derjenigen beschämen, welche glaubten, daß der Witz nur zu einer eitlen Belustigung gut sey. [...] Welch ein vortrefflicher Freund sind Sie! Ich fühle den ganzen Werth ihrer Freundschaft. Sie kennen Ihren Rabener, der nicht gern beleidigt, aber noch weniger schmeichelt. Und wenn ich Ihnen sage, daß Sie meynen Beifall haben, daß Sie die Welt gewiß erbauen werden und daß Sie alle Leser von Ihrem guten Herzen überzeugen; so sage ich Ihnen eine Wahrheit, die Ihnen meine Freundschaft und mein Geschmack schuldig sind. ${ }^{98}$

95. S. Martus fasst dieses Phänomen unter die Begriffe der „Verbesserungsästhetik“ sowie der „Temporalisierung der Poesie“. Vgl. ibid., S. 27-43.

96. Johann Andreas Cramer, Christian Fürchtegott Gellerts Leben, Leipzig, 1774, S. 85.

97. Rabener, Briefwechsel, Nr. 137, S. 207.

98. Rabener an Gellert, Dresden 25. März 1757, in Rabener, Briefwechsel, Nr. 137. 